\title{
Psychology of Business Intelligence Tools: Needs-Affordances-Features Perspective
}

\author{
Kaveh Abhari \\ San Diego State University \\ kabhari@sdsu.edu
}

\author{
Alessandro Vomero \\ San Diego State University \\ avomero@sdsu.edu
}

\author{
Elizabeth J. Davidson \\ University of Hawai'i at Mānoa \\ edavidso@hawaii.edu
}

\begin{abstract}
This study applied the Needs-AffordancesFeatures (NAF) framework to study psychological motivations behind the use of Business Intelligence (BI) tools especially when the use of such tools is voluntary. Our findings suggest that psychological needs motivate the use of BI tools that provide 13 affordances to fulfill five psychological needs, namely autonomy, competence, relatedness, having a place and selfrealization. These affordances were identified through a review of six publicly available BI tools. This study posits that three groups of affordances-creation, collaboration, and communication-explain the relationship between psychological needs and applications of BI. This study generates important implications for BI research by providing an overarching framework for the affordances of BI tools as $a$ whole and explaining the importance of psychological needs that motivate the use of BI tools. The results also provide a new lens and common vocabulary for future studies and design of BI tools.
\end{abstract}

\section{Introduction}

Business Intelligence (BI) applications have been studied from individual users' perspectives since the introduction of 'BI for everyone' and 'Self-Service BI' in the early 2010s. However, while research on BI technologies and benefits has rapidly proliferated, only a limited number of studies have discussed its adoption by individual users, particularly in contexts where the use of such tools is voluntary. To realize the full potential value of BI tools in organizations, it is important that knowledge workers (users), who are not explicitly tasked as their job to produce BI reporting (i.e. data analysts), creatively and voluntarily experiment with and apply BI tools to their own jobs. Unfortunately, many organizational BI efforts fall far short of attaining employees' voluntary adoption and use of BI. This paper addresses this issue by examining the psychological needs that may drive the use of BI tools, beyond the organizational needs or mandates that typically are addressed in BI research. We adopt this approach because psychological needs theory provides an analytical lens generalizable across users in different settings to develop insights into knowledge workers' motivations for adopting their use. Factors such as social or technical support influence system use, but are they are more contextually bounded.

In this paper, the term 'BI tools' refers to a collection of data processing technologies that support decision-making by offering features such as data querying, cleansing, processing, visualizing, analyzing, and reporting. Accordingly, we define BI as a system with a wide array of processes and technologies used to collect, analyze, and disseminate data for better decision making [17]. In this paper, 'BI user' refers to an employee who has access to at least one BI tool and has basic knowledge on how to use that tool. Different BI tools have different affordances, which might address different set of users (or organizational) needs.

To focus the scope of this paper we propose, on one hand, to enhance the understanding of the psychological needs and affordances for BI tools, and on the other hand, to clarify how needs and affordances provide a more integrated understanding of the use of these tools. This integrated view of BI tools develops a practical framework to address the following questions: (a) What innate psychological needs do users attempt to fulfill by using BI tools? (b) What are the relevant affordances that BI tools provide to fulfill these needs?

To initiate a robust discussion on the psychological aspects of BI systems, we applied the NeedsAffordances-Features (NAF) framework [29]. The NAF framework synthesizes all major motivation theories commonly used in IS research, including ERG Theory (existence, relatedness, growth), Hierarchy of Needs, Learned Needs Theory, Self-Determination Theory and Psychological Ownership Theory to identify psychological needs and relate these needs to 
technology affordances [29]. We use the NAF framework to explain how fundamental psychological needs justify the use of BI tools and identify certain affordances of BI that satisfy such needs. While existing research focuses on situational, procedural or existential reasons such as completing a task or improving performances, we focused on psychological needs such as autonomy, relatedness, and competence to explain the underlying mechanism behind users' personal motivations to use BI tools. We believe this approach not only helps explains the underutilization of BI systems but also informs designers' and managers efforts to improve BI operations and technologies.

The power of needs-based theories resides in the fact that they can help explain why employees use certain BI features or demand certain affordances, especially when there is no operational requirement (e.g. reporting mandate). This approach to BI research is increasingly important since the introduction of selfservice BI systems as these systems promote the voluntary use of BI tools across organizations. We posit that the NAF framework, to a great extent, can explain the affordances of BI tools pertaining to the fulfillment of users' psychological needs beyond organizational or procedural mandates.

To achieve these goals, we first discuss psychological needs based on the NAF framework; then, we analyze the features of six available BI tools and map their features and affordances following this literature. In this way, we identified 13 affordances in three groups-creation, collaboration, and communication - and discuss how these affordances satisfy five psychological needs, namely autonomy, competence, relatedness, having a place, and selfrealization. We conclude with five propositions that offer a theoretically grounded mechanism to identify relevant psychological needs pertinent to BI features, the key affordances of BI tools, and the association between the identified needs and BI affordances.

This paper contributes a systematic approach to identifying key psychological needs and affordances of BI tools driving the use of these tools, especially in the absence of organizational or procedural mandates. Our propositions help build foundations for further research on BI adoption and implementation strategies. From a practical perspective, this paper can aid in the design of new BI tools and features to better fulfill organizational needs through understanding BI users' psychological needs. This also promises to assist BI developers in enhancing the affordances of BI tools to further encourage voluntary use of BI applications.

\section{Background}

Business Intelligencer, or BI, is the ability of an organization or business to reason, plan, predict, solve problems, think abstractly, comprehend, innovate and learn in ways that increase organizational knowledge, inform decision processes, enable effective actions, and help to establish and achieve business goals [8]. BI is often used as an umbrella term for large-scale decision support systems (DSSs) in organizations. Surveys by industry analysts and vendors consistently find that BI development and deployment is one of the highest priorities for CIOs [2]. However, it is crucial to make a distinction between the different roles of BI within a company. Arnott et al. define the uses of BI by dividing them into different business roles: operational, professional and strategic [2]. In this study, we focus on the professional role to be able to discuss BI concepts from need-based theories and generalize the findings to different contexts with different operational needs and strategic goals.

Professional use of BI is typically viewed as a knowledge creation capability to generate organizational value. Professional users look for BI tools to support their daily activities and to enhance their decision-making process. In this sense BI-related needs are mainly individual needs -for example, related to responsibilities within a functional unit- to enhance individuals' own performance outcomes. This is in contrast with operational and strategic views of $\mathrm{BI}$, which are focused on procedural and strategic needs of the organization, respectively [2]. Assuming users can associate BI with potentially addressing their professional needs, they are willing to find new ways or knowledge to make better decisions in order to fulfill these needs more effectively and efficiently.

From this perspective, BI resources (or inputs) are information, and outputs are data-driven decisions. BI success depends on the quality and timing of these decisions, related but not limited to managerial functions such as planning, controlling, organizing, and directing. In particular, BI can enable or enhance the first phase of the decision-making process which includes intelligence, design, choice, and implementation [13]. We focus on the intelligence phase, in which reality is analyzed in order to infer intelligence requirements. Intelligence can be gathered, processed, and disseminated individually or collectively. Hence, our focus in this paper is on understanding the psychological needs driving actions within the intelligence phase for professional use of BI tools, especially without procedural obligations or organizational mandates.

\subsection{Professional BI Needs}

The NAF framework helps us to define what a professional 'need' is and how the concept of needs could be translated into an information-oriented environment. In this paper, a professional need can be 
defined as a learning or performance gap between the current and the desired state [33]. Therefore, in an information-oriented environment, a professional need can become an information need which is defined as the gap between the current information or knowledge available and the information required to make certain decisions in order to perform a task, solve a problem or achieve a goal [4]. In this realm, "needs assessment" can be defined as a process aimed at overcoming the gap between these two states [33]. The purpose of this assessment is mainly about making better decisions and providing support to justify those decisions in order to enhance professional outcomes.

By contextualizing this logic for individual decision-makers_professionals—we posit that BI users are willing to utilize BI tools to narrow the information or knowledge gap in order to improve their decision-making process and its outcomes. We identify three ways BI users try to improve this process or its outcomes: knowledge creation in support of a decision (including gaining insight into the decision context), improving the decision in collaboration with other users, and communicating the decision. However, previous studies have demonstrated that these actions vary, even in the same business context where we might expect consistency [2]. If we assume that professional needs are typically characteristic of a specific decision context, the dissimilarities in BI tool usage must stem from individual psychological needs. Therefore, we need to identify individual needs to fully understand, explain, and assess the differences in BI usage.

\subsection{Psychological BI Needs}

In psychology, individual needs are described as essential nutriments for individual growth as they give purpose and direction to behavior and motivate action toward a goal. Individuals tend to pursue those needs in order to fulfill their own potential and reach well-being [11]. The organizational psychology literature also suggests that individuals are motivated to take actions that are more likely to satisfy their psychological needs [8]. Previous studies used various theories such as SelfDetermination, Theory of Need, ERG Theory, and Goal Contents Theory to explain the relationship between employees' psychological needs and their actions [28, $55,56]$. The NAF framework suggests a combination of self-determination and psychological ownership theories. For this study, we consider five psychological needs identified in the NAF framework based on an extended model of self-determination theory: autonomy, competence, relatedness, having a place and self-realization [9, 29].

2.2.1. Autonomy. Autonomy is the capacity to make an informed, uncoerced decision. Deci and Ryan defined autonomy as “an individual's innate psychological need to be a causal agent of one's own life and act in harmony with one's integrated self'. To act consistently, an individual should act via a free volitional choice [8]. Decision support systems are known to bring some sense of autonomy among employees. Thus autonomy refers to a level of discretion granted to an employee in decision-making processes which can include decisions about the use of specific tools or features, data analysis procedures or assessment of results implications [9]. Knowledge created or shared by BI tools is the first and most important component of the decision-making process which leads to enhancing autonomy [12].

2.2.2. Competence. Competence is an innate psychological need that expresses the will to be effective in dealing with the environment in which one finds oneself [10]. Competence also refers to personally being capable of having an impact on the surrounding environment and of achieving valued outcomes [8]. The literature consistently reports that the individual employee's competencies such as curiosity and selfdirection are one of the major reasons for organizational effectiveness $[40,46]$. In the last decade, BI researchers and practitioners have focused on developing tools and techniques for business analysts to develop or support competencies such as data-driven decision-making, critical analysis, problem-solving and collaboration.

2.2.3. Relatedness. Relatedness is defined as "to love and care and to be loved and cared" [11]. Relatedness is the psychological need to interact, to be connected, and experience caring for others. In a business environment, relatedness as a need refers to the collaboration, sense of belonging, and support within and among teams [3]. BI tools can improve the overall connectivity of the enterprise and consequently empower its users to effortlessly connect and effectively interact. The integration of BI and other networking tools has been also taken by business decision-makers as an effective means to enhance employee connectedness [14].

2.2.4. Having a place. Having a place refers to an individual need to have a safe and recognized place to claim an identity or influence. Having a place in an organization can be directly related to how BI users tend to create their own environment to work and produce insights, like data sandboxes for analysis, reports for knowledge sharing and BI use profiles for reputation building [50].

2.2.5. Self-realization. Self-realization refers to a desire to self-present and self-differentiate, and it has 
three dimensions: 'coming to know the self', 'expressing self-identity' and 'maintaining continuity of self-identity' [45]. By satisfying this need, employees are able to fully or partially exploit their sense of mastery over the environment [19]. BI tools provide their users the ability to identify themselves by recognizing, confronting, and solving problems, thereby reaching a higher state of self-realization. In this study, we focus on self-realization needs.

\section{BI Affordances and Features}

The concept of affordances is relatively recent and has different connotations depending on the field of interest. Generally speaking, affordances can be defined as "action possibilities afforded by technology to users, or affordances are what a user can potentially do through using the technology" [28]. Since affordances are actions permitted by features [16], affordances can be used as an intermediary concept between needs and BI features [29]. According to the NAF framework, a set of psychological needs might be fulfilled by a set or a single affordance, which in turn might use a single feature or a set of features not be directly related to the specific needs. Thus, we suggest there are benefits in theorizing the relationships between needs and affordances rather than needs and features of BI tools, as has been done in previous studies. We focus on designed affordance that BI tool designers anticipate users will take advantage of.

To identify affordances and features, we reviewed BI literature and examined six BI tools: QlikView, Palo BI, JasperSoft, Tableau (Public), Knowage (SpagoBI) and Pentaho. These tools share common features such as data connection and integration, data visualization, basic analysis, reporting, and dashboard creation. To identify common features of these BI tools, we focused on open-source or publicly available tools because of their popularity and accessibility [6]. Table 1 provides the list of tools and their common features reviewed for this study, as suggested by Brandão et al. [6]. While the list of features is not exhaustive, it provides an overview of commonly used features cited by users.

To generate a comprehensive set of $\mathrm{BI}$ tool affordances from these features, we synthesized the affordances examined by prior research and affordances emerging from the review of features (Table 1). First, we started with a comprehensive review of prior literature that had identified affordances of various decision support and knowledge management systems. We then synthesized and integrated the identified affordances to generate an initial list of distinct, BI tool affordances. As a result, we identified 13 affordances driven by these features: Reporting, Browsing, Self-Promotion, Sharing, Cooperation, Knowledge Management, Group
Management, Interactivity, Discovery, Detection, Prediction, Prescription, and Monitoring.

Table 1. Features summary of sample BI tools

\begin{tabular}{|c|c|}
\hline TOOL & FEATURES \\
\hline $\begin{array}{l}\text { QlikView } \\
\text { End-to-end data } \\
\text { management, } \\
\text { reporting and } \\
\text { analytics platform }\end{array}$ & $\begin{array}{l}\text { - } \text { Multi-source data integration } \\
\text { - } \text { In-memory data processing } \\
\text { - Live data extraction } \\
\text { - } \text { Visuals } \\
\text { - } \text { Dashboards }\end{array}$ \\
\hline $\begin{array}{l}\text { Palo BI } \\
\text { Multiple users and } \\
\text { multidimensional in- } \\
\text { memory OLAP, with } \\
\text { online worksheet } \\
\text { server }\end{array}$ & 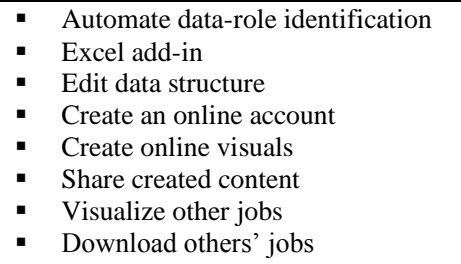 \\
\hline $\begin{array}{l}\text { JasperSoft } \\
\text { Reporting, } \\
\text { dashboards, analysis, } \\
\text { and data integration } \\
\text { services for both } \\
\text { stand-alone and } \\
\text { embedded BI with } \\
\text { five modules: } \\
\text { Designer (D), Soft } \\
\text { Reports (SR), Soft } \\
\text { Reports Server } \\
\text { (SRS), OLAP (O) } \\
\text { and ETL (E) }\end{array}$ & $\begin{array}{ll}\text { - } & \text { Create reports, visuals, tables, } \\
& \text { dashboards (D) } \\
\text { - } & \text { Data integration (D) } \\
\text { - } & \text { High-quality printing (SR) } \\
\text { - } & \text { Publish jobs online (SRS) } \\
\text { - } & \text { Comment on others' jobs (SRS) } \\
\text { - } & \text { Shact to others' jobs (SRS) } \\
\text { - } & \text { Download (SRS) } \\
\text { - } & \text { Access conthers' jobs (SRS) } \\
\text { - } & \text { Data query, slice, and dice, pivot, } \\
& \text { filter, summarize (O) } \\
\text { - } & \text { Data mart/warehouse creation and } \\
& \text { management (E) }\end{array}$ \\
\hline $\begin{array}{l}\text { Tableau (Public) } \\
\text { Interactive data } \\
\text { visualization tool } \\
\text { allowing one to } \\
\text { publish one's visuals, } \\
\text { dashboard, and } \\
\text { stories online }\end{array}$ & $\begin{array}{l}\text { - } \text { Online data analytics } \\
\text { - } \\
\text { - } \text { and summarize } \\
\text { - } \text { Personal account creation } \\
\text { - } \text { Download others' jobs } \\
\text { - } \text { Interactivity of filters, visuals, and } \\
\text { - } \text { dashboards } \\
\text { - } \text { Live extraction } \\
\text { - } \text { Putomatic data role identification } \\
\text { Predictive analytics }\end{array}$ \\
\hline $\begin{array}{l}\text { Knowage } \\
\text { (SpagoBI) } \\
\text { Open source BI suite } \\
\text { covering various } \\
\text { analytical needs with } \\
\text { five modules: Server } \\
\text { (S), Studio (ST), BI- } \\
\text { Meta (M), SDK (K) } \\
\text { and App (A) }\end{array}$ & $\begin{array}{ll}\text { - } & \text { Online data analytics (S) } \\
\text { - } & \text { Desktop application (ST) } \\
& \text { Visuals, dashboards, OLAP, and } \\
\text { - } & \text { Data integration (M) } \\
\text { - } & \text { Easy metadata querying (M) } \\
\text { - } & \text { Account creation (K) } \\
& \text { Download, comment, react, open } \\
& \text { others' jobs (K) } \\
\text { - } & \text { Predictive analytics (A) }\end{array}$ \\
\hline $\begin{array}{l}\text { Pentaho } \\
\text { Open source BI } \\
\text { software providing } \\
\text { data integration, } \\
\text { OLAP services, } \\
\text { reporting, and ETL, } \\
\text { Platform (B), } \\
\text { Reporting (R), } \\
\text { Analysis (A), Data } \\
\text { integration (D), } \\
\text { Dashboard (S) and } \\
\text { Weka (W) }\end{array}$ & 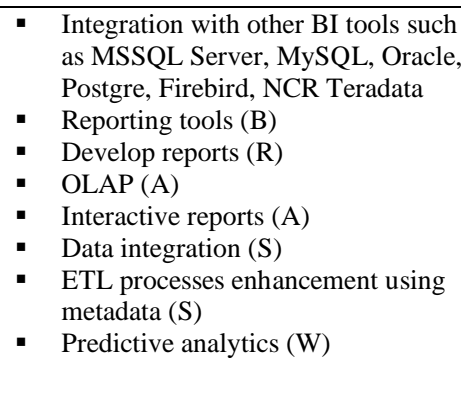 \\
\hline
\end{tabular}


To validate the legitimacy and inclusiveness of our identified affordances, we examined three new cases of BI tools, namely, IBM Cognos Analytics, Sisense, and Microsoft Power BI. We mapped the features of these tools to the affordances that we had identified to ensure our affordances collectively accounted for all the common features. Finally, we grouped the affordances into three categories based on their similarities in terms of users' goals: communication, collaboration, and creation affordances $[1,21]$. The results of this process are summarized in three groups: communication affordances, collaboration affordances, and (knowledge) creation affordances. (Tables 2-4)

The first group, creation affordances, reflect knowledge creation possibilities that are self-sufficient and do not necessarily require others in order to be actualized. These affordances were traditionally associated with three types of analytics: descriptive, predictive and prescriptive. In this study we expanded this view in order to be more specific in terms of features enabling knowledge creation activities. This group includes the affordances of Discovery, Detection, Prediction, Prescription, and Monitoring.

Table 2. BI tools' knowledge creation affordances

\section{CREATION AFFORDANCES}

Discovery

Use BI tools to discover patterns related to, preferences,

performance, etc. to inform decision-making [30, 53]

Example

Tableau and Palo BI automatic data role identification;

Tableau public joint between dataset; Palo BI converts

data sets into multi-dimensional in-memory OLAP

\section{Events Detection}

The use of monitoring tools in combination with rule engines enables the user to identify meaningful events in

a timely manner mainly for diagnostic analysis [53]

$$
\text { Example }
$$

Qlik real-time alert emails allow users to be informed about critical events in a timely manner

\section{Prediction}

The use of BI tools to observe trends and make predictions [53, 54, 57]

\section{Examples}

Forecasting tools in Tableau, Spago BI, and Pentaho used to predict future trends

\section{Prescription}

The use of BI tools to ideate a new solution to specify a preferred course of action, improve future performance or avoid future errors

\section{Example}

Using Tableau cluster analysis to inform segmentation

$$
\text { Monitoring }
$$

Tracking systems may allow gathering data and presenting data in real-time $[5,51,53,57]$

$$
\text { Example }
$$

Multisource data integration and online analytics available through Spago, JasperSoft, and Tableau used for a rapid pain-points identification
The second group, collaboration affordances, reflect action possibilities that are collaborative in nature and include the involvement of others - not necessarily cooperation but dynamic knowledge management. These affordances enable collaborative knowledge management and include Cooperation, Knowledge Management, Group Management, and Interactivity (e.g., of collaborative dashboards). Affordances in this group are mainly focused on the enablers of knowledge co-creation rather than knowledge exchange.

Table 3. BI tools' collaboration affordances COLLABORATION AFFORDANCES

\section{Cooperation}

Users can cooperate with each other in creating, analyzing, or editing content like dashboard [25] Example

Pentaho integration with MS Office 365, enabling live collaboration

\section{Knowledge management}

Users can manage, and disseminate knowledge to other users at different organizational levels [31, 39, 49]

\section{Example}

Share dashboards, stories with the community for feedback on Tableau

\section{Group management}

Users can create and manage teams or interest groups to facilitate access to information, teamwork and collaboration [31]

\section{Example}

Jaspersoft SoftReports Server can be used to grant/deny access to database and analytics based on access policies

Interactivity

Users can create visuals, dashboards, and stories that can be altered, commented on or personalized by final users to facilitate collaboration $[20,26]$

\section{Example}

Interactive filters on Tableau Public; drilling functions feature selection by Qlik; interactive reports creation on Pentaho Analysis module

The third group, communication affordances, enable the goal-directed communication of intelligence or knowledge and include Browsing, Reporting, SelfPromoting, and Sharing. Unlike collaboration affordances, these affordances do not necessarily require reciprocity but do emphasize the social aspects of knowledge sharing [14, 36]. Communication affordances can contribute to the formation of socioprofessional communities of users (both online and offline) and ultimately facilitate the process of knowledge creation and collaboration using BI tools. However, actualizing these affordances such as browsing can be independent form actualizing creation or collaboration affordances such as collaborative knowledge creation. 
Table 4. BI tools' communication affordances COMMUNICATION AFFORDANCES

\section{Reporting}

Users can directly communicate findings, comments, and results with teammates and interested parties [7, 35]

Example

BI tools with online modules such as Tableau enable users to create content and share it on various forms and platforms (Websites, apps, reporting services)

\section{Browsing}

User can browse BI content generated by others; create, receive and share alerts when contents of interest are updated $[7,29,32]$

\section{Example}

Watch others' contents on Palo Bi-Worksheet Server, where query, slice, and dice, combined with analytics functionality, allows information extraction

\footnotetext{
Self-promotion

Users can present information related to their BI activity or their results on the enterprise network [33, 41, 53]

\section{Example}

Creating personal profiles using tools such as Tableau Public, Spago BI, Palo BI
}

\begin{tabular}{l} 
Sharing \\
Users share new content to support problem-solving, \\
improving performance, etc. [17, 18, 48] \\
Example \\
Pentaho users can postscripts directly on GitHub using \\
in-app implementations to support other users \\
\hline
\end{tabular}

\section{Propositions}

The objective of this study is to provide a thread that connects features of BI tools, their affordances, and the psychological needs that these affordances may satisfy and thus will motivate use of BI tools evidencing these affordances. We use this logic to develop five propositions explaining the relationships between five psychological needs and three groups of affordances. Our literature review provides supporting evidence to our theorization of how these three groups of affordances and five psychological needsAutonomy, Relatedness, Competence, Having a Place, and Self-Realization - are related [14, 22, 24, 28, 36, 38]. Table 5 summarizes the results of our mapping process where each affordance can satisfy more than one psychological need. The final framework is presented in Figure 1.

\subsection{Need for Autonomy}

Autonomy can be considered as the capacity to make an informed, un-coerced decision [9]. If we assume that the decision-making process should be data-driven, then access to a tool to extract, clean, interpret, and share actionable knowledge is a necessity [8]. All BI tools studied provide such affordances enabled by a combination of features. For instance, communication affordances enable users to create and share interactive dashboards to convey their decision rationales and it involves using various features such as data modeling, visualization, reporting, and sharing. Creation affordances also enable BI users to make an informed decision through analytics or monitoring, therefore giving users more agency in controlling trends, decision-making and problem-solving. Similarly, collaboration affordances give BI users a voice through active participation in knowledge creation or dissemination which in turn actualize affordances such cooperation and knowledge management. Therefore, we posit:

Proposition I: The need for autonomy in a business environment motivates the use of BI tools that afford creation, collaboration, and communication.

Table 5. Mapping psychological needs to the BI affordances that satisfy these needs

\section{NEEDS}

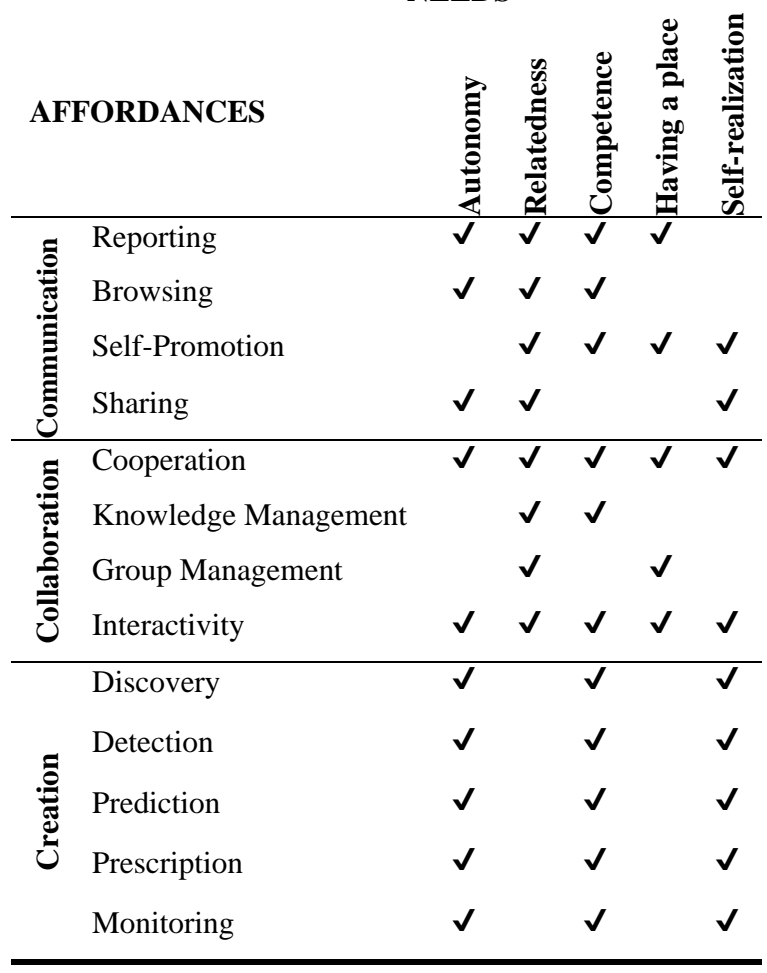

\subsection{Need for Relatedness}

Social aspects of BI tools enabled by creating a profile and sharing across functional units can help fulfill users' need for relatedness. Modern BI tools such as Tableau and Power BI enable social-media-like actions such as self-presentation, presence signaling, 
relationship formation, group management, metavoicing, communication, and collaboration, which enable creating a broader connection between users [29]. Additionally, relatedness for BI users also refers to the need for support and collaboration among teams and team members [3]. Such needs can be fulfilled firstly by implementing a BI collaborative tool like Tableau online or other software suites with similar functionality-assuming that the business culture is fairly collaborative and competitive. Secondly, support relatedness by providing a reliable network of users and letting them know whether there are other users available to collaborate [23]. Thirdly, relatedness needs can be satisfied by reaching a broader audience and educating teams on how to join the communities/groups and contribute [27, 34]. Affordances like collaboration are enabled by different features, from online collaboration (e.g. Tableau) to integration features (e.g. Pentaho's integration with MS Office 365). Yet communication affordances help users to fulfill the need for relatedness by allowing them to create personal profiles on online BI tool modules like Tableau Public, Spago BI, and Palo BI. Further, communication affordances can satisfy the need for the relatedness by sharing the results of work with a larger community of users. Therefore,

Proposition II. The need for relatedness in a business environment motivates the use of BI tools that afford collaboration and communication.

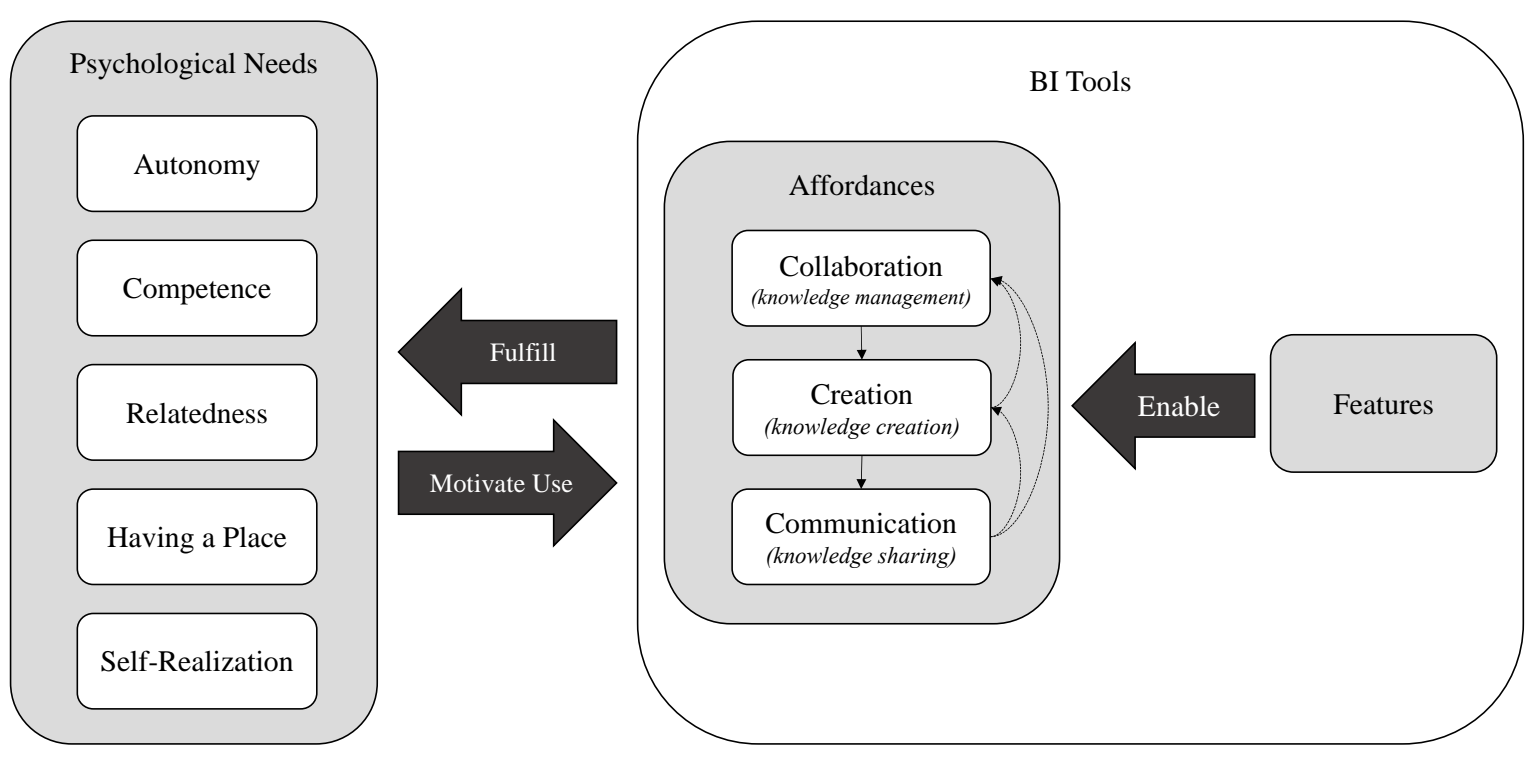

Figure 1. The NAF framework contextualized from general model for BI tools and applications [28]

\subsection{Need for Competence}

Feeling competent entails having the necessary capability, knowledge, or skill to compete tasks successfully [29] [10]. Translated to the BI context, competence is the need that BI users have to be productive and achieve valued outcomes. Thus, BI users in need of competence seek affordances that allow them to expand knowledge, capabilities, and control. Competence is developed through creation, collaboration and communication as all three affordances, if actualized, offer opportunities to gain and sharpen a group of skills. For example, BI tools afford diagnostic analysis by offering features such as merging one or more data source, extracting relevant information, creating actionable knowledge. Likewise, through communication and collaboration affordances, BI users can weigh the access to certain information in order to "control and alter an environment" in terms of knowledge creation, presentation and sharing [52]. Therefore:

Proposition III. The need for competence in a business environment motivates the use of BI tools that afford creation, collaboration, and communication.

\subsection{Need for having a place}

'Having a place' can be interpreted as the will to possess a portion of the environment for the sake of safety and control [44]. In the BI context, this need is directly related to the desire to create one's own environment to work and produce insights like data sandboxes for analysts. This need in a business environment can be fulfilled by allowing professional users to create, modify, and have the control of their own BI environment [29]. For example, through 
communication affordances such as self-presentation, users can create their own personal space online where they can load their datasets, slice and dice, infer, create visuals and reports and test their creations. Moreover, having a place can also be satisfied by allowing users to interact and personalize their data work environment [43]. From this perspective, the "having a place" need can be satisfied through collaboration affordances such as interactivity that allows customizing analysis and dashboards created by others for personal use. Therefore,

Proposition IV. The need for having a place in a business environment motivates the use of BI tools that afford collaboration and communication.

\subsection{Need for self-realization}

Finally, self-realization is defined as the will to exploit or actualize one's potential. According to Maksimenko and Serdiuk, self-realization entails personal readiness to manifest inclinations and capabilities, suggesting balanced and harmonious development of different aspects of a person with the application of adequate efforts to expand personal potential [37]. That is, self-realization is the transformation of opportunities or competencies into reality. In a business environment, this need can be fulfilled through creation and collaboration affordances. By adopting BI tools, users may be able to utilize data to expand their role and realize their potential in decision-making and problem-solving, either individually or collaboratively. Communication affordances similarly help BI users to satisfy their selfrealization needs by sharing their insight and achievements. Therefore,

Proposition $\boldsymbol{V}$. The need for self-realization in a business environment motivates the use of BI tools that afford creation, collaboration, and communication.

\section{Conclusion and Future Studies}

The use of BI tools to facilitate knowledge creation, knowledge sharing, and knowledge management is growing. Yet, little is known about how and why these technologies may be utilized by employees across the organization when there is no operational mandate to use them. This merits further investigation since these tools not only empower employees to fulfil their performance goals (e.g. through data-driven decision making) but also give them a means to achieve their individual aspirations (e.g. recognition).

In this study, we specifically focused on psychological needs as the well-known predictor of self-regulated and voluntary actions [47]. We also used an affordance lens to understand the mutuality of employees' intentions and BI tool capabilities that provide the potential for a particular set of actions [15, 42]. We then used the NAF framework to develop a foundation to study the application of BI tools in relationship with psychological needs. Our study involves identifying the functional affordances of BI tools enabled by different features as well as the needs that these affordances fulfill. As a result, we posited five propositions that provide a theoretical foundation that future studies can leverage to explore and explain the use of various types of BI tools. For example, our findings suggest that affordances have complementary effects, and therefore, a specific combination of affordances may provide superior means to fulfill a psychological need. Similarly, a specific combination of features can also provide a specific affordance in a superior way. In this situation, BI users may select a combination of features that most directly fulfill the psychological need.

This study also provides insights into the underlying mechanism (affordances) by which BI features can satisfy psychological needs. Therefore, the results can help BI researchers and practitioners predict the psychological needs that motivate the use of a specific group of BI features. This offers insight into the design and evaluation of BI tools in a more systematic way. Therefore, BI tool developers can draw upon our results to provide guidelines for how to study users' psychological needs before developing new features. BI advocates can also employ the findings to better promote affordances of BI tools to facilitate adoption and improve applications.

By using an affordance lens to explore BI technology, we call for a shift in how BI tools are selected by organizations and how these tools are introduced to the employees. The affordance lens also allows the integration of BI technology with individual needs, and thus it provides a valuable foundation for BI training and support. Finally, by identifying how different knowledge mechanisms are enabled by different affordances, we offer a specific way forward to theorize how BI tools can be leveraged in knowledge creation, sharing and management.

Lastly, this preliminary study highlights the need to consider users' psychological needs (versus operational needs) to further create value from BI tools. For example, managers with sufficient understanding of users' (personal) needs might be able to motivate more frequent and in-depth use of BI tools in order to achieve strategic and operational goals. Our study could assist in the design of knowledge management procedures that rely on BI tools and outcomes in which particular uses (realized affordances) also satisfy individual professional's psychological needs. In this 
way managers could better prioritize BI investments including training, implementing complementary BI capabilities and establishing new data-driven processes that encourage voluntary use of BI and related technologies.

BI researchers can leverage our propositions to design both qualitative and quantitative studies that help identify psychological needs, examine the relationships between needs and applications, and characterize the affordances of BI tools. The effects of different features, individually or collectively, on perceived affordances also merit further examination. Since our study was limited to publicly available BI tools, future studies can validate our findings by examining a different set of tools and contextualize the use of such tools to a specific environment.

\section{References}

[1] Abhari, K., E.J. Davidson, and B. Xiao, "Co-Innovation Platform Affordances: Developing a Conceptual Model and Measurement Instrument", Industrial Management \& Data Systems 117(5), 2017, pp. 873-895.

[2] Arnott, D., F. Lizama, and Y. Song, "Patterns of business intelligence systems use in organizations", Decision Support Systems 97, 2017, pp. 58-68.

[3] Arora, A., and A. Gambardella, "Complementarity and External Linkages: The Strategies of the Large Firms in Biotechnology", The Journal of Industrial Economics 38(4), 1990.

[4] Aura, T., "Assessment of Managerial Information Needs as a Basis for Business Intelligence Development", 2016.

[5] Berezina, K., A. Bilgihan, C. Cobanoglu, and F. Okumus, "Understanding Satisfied and Dissatisfied Hotel Customers: Text Mining of Online Hotel Reviews", Journal of Hospitality Marketing \& Management 25(1), 2016, pp. 1-24.

[6] Brandão, A., E. Pereira, M. Esteves, “A benchmarking analysis of open-source business intelligence tools in healthcare environments", Information (Switzerland) 7, 2016.

[7] Davis, A., J. Murphy, D. Owens, D. Khazanchi, and I. Zigurs, "Avatars, people, and virtual worlds: Foundations for research in metaverses", Journal of the Association of Information Systems 10(2), 2018, pp. 90-117.

[8] Deci, E.L., and R. Flaste, Why we do what we do: understanding self-motivation, Infogain Publication, 1996.

[9] Deci, E.L., A.H. Olafsen, and R. Ryan, "SelfDetermination Theory in Work Organizations: The State of a Science", The Annual Review of Organizational Psychology and Organizational Behavior 4(1), 2017, pp. 19-43.

[10] Deci, E.L., and R.M. Ryan, "A motivational approach to self: integration in personality.", Nebraska Symposium on Motivation 38, 1990, 237-288.

[11] Deci, E.L., and R.M. Ryan, "The 'what' and 'why' of goal pursuits: Human needs and the self-determination of behavior", Psychological Inquiry 11(4), 2000, pp. 227-268.

[12] Duan, Y., V.K. Ong, M. Xu, and B. Mathews,
"Supporting decision making process with 'ideal' software agents - What do business executives want?”, Expert Systems with Applications 39(5), 2012, pp. 5534-5547.

[13] Dursun Delen, E.T.R.S., Business intelligence and analytics: Systems for Decision Support, Pearson, 2014.

[14] Ellison, N.B., J.L. Gibbs, and M.S. Weber, "The Use of Enterprise Social Network Sites for Knowledge Sharing in Distributed Organizations", American Behavioral Scientist 59(1), 2015, pp. 103-123.

[15] Faraj, S., and B. Azad, "The Materiality of Technology: An Affordance Perspective”, In P.M. Leonardi, B.A. Nardi and J. Kallinikos, eds., Materiality and Organizing: Social Interaction in a Technological World. Oxford University Press, Oxford, 2012, 237-258.

[16] Fayard, A.L., and J. Weeks, "Affordances for Practice", Information and Organization 24(4), 2014, pp. 236-249.

[17] Frederiksen, A., "Competing on analytics: The new science of winning", Total Quality Management \& Business Excellence 20(5), 2009, pp. 583-583.

[18] Furmankiewicz, J., M. Furmankiewicz, and P. Ziuziański, "Implementation of Business Intelligence Performance Dashboard for the Knowledge Management in Organization", Zeszyty Naukowe Politechniki Śląskiej 1940(1), 2015, pp. 43-60.

[19] Galderisi, S., A. Heinz, M. Kastrup, J. Beezhold, and N. Sartorius, "Toward a new definition of mental health", World Psychiatry 14, 2015, 231-233.

[20] Giraldo Marín, L.M., M.S. Tabares Betancur, and L. Joyanes Aguilar, "Interactivity Model 2.0: Social communication dynamics in organizational contexts", Journal of Business Research 69(11), 2016, pp. 4947-4952.

[21] Gloor, P.A., Swarm creativity: competitive advantage through collaborative innovation networks, Oxford University Press, New York, 2006.

[22] Glowalla, P., C. Rosenkranz, and A. Sunyaev, "Evolution of IT Use: A Case of Business Intelligence System Transition", International Conference on Information Systems (ICIS 2014), (2014), 1-19.

[23] Goel, L., N. Johnson, I. Junglas, and B. Ives, "Predicting users' return to virtual worlds: A social perspective", Information Systems Journal 23(1), 2013, pp. 35-63.

[24] Gressgård, L.J.L., "Text-Based Collaborative Work and Innovation: Effects of Communication Media Affordances on Divergent and Convergent Thinking in Group-Based Problem-", Journal of Information, Knowledge, and Management 7, 2012.

[25] Harindranath, G., E.W.N. Bernroider, and S.H. Kamel, "Social Media and Social Transformation Movements: the Role of Affordances and Platforms", Proceedings of the European Conference on Information Systems Paper 73, 2015, pp. 1-13.

[26] Ichihara, A., and O. Nizam, "The use of business intelligence tools to analyze the influence of interactivity and interaction factors on the assessment of distance students' performance in virtual learning environments", International Journal of Learning, Teaching and Educational Research 17, 2018, 91-101.

[27] Jenkins-Guarnieri, M.A., S.L. Wright, and L.M. 
Hudiburgh, "The relationships among attachment style, personality traits, interpersonal competency, and Facebook use", Journal of Applied Developmental Psychology 33(6), 2012, pp. 294-301.

[28] Karahanna, E., S. Xin Xu, Y. Xu, and N. (Andy) Zhang, "The Needs-Affordances-Features Perspective for the Use of Social Media", MIS Quarterly 42(3), 2018, pp. 737-756.

[29] Karahanna, E., S. Xin Xu, Y. Xu, and N. (Andy) Zhang, "The needs-affordances-features perspective for the use of social media”, MIS Quarterly 42(3), 2018, pp. 737-756.

[30] Karjaluoto, H., N. Mustonen, and P. Ulkuniemi, "The role of digital channels in industrial marketing communications", Journal of Business and Industrial Marketing 30(6), 2015, pp. 703-710.

[31] Kietzmann, J.H., K. Hermkens, I.P. McCarthy, and B.S. Silvestre, "Social media? Get serious! Understanding the functional building blocks of social media", Business Horizons 54(3), 2011, pp. 241-251.

[32] Kreijns, K., and P. Kirschner, "The Social Affordances of Computer-Supported Collaborative Learning Environments", ASEE/IEEE Frontiers in Education Conference, (2001), pp. 12-17.

[33] Lee, J., "A Practical Guide to Needs Assessment, 2nd Edition”, Human Resource Development International 10(4), 2007, pp. 478-480.

[34] M., V., A. Syed, A. Mohammad, and M. N., "Pentaho and Jaspersoft: A Comparative Study of Business Intelligence Open Source Tools Processing Big Data to Evaluate Performances", International Journal of Advanced Computer Science and Applications 7(10), 2016.

[35] Majchrzak, A., S. Faraj, G.C. Kane, and B. Azad, “The Contradictory Influence of Social Media Affordances on Online Communal Knowledge Sharing", Journal of Computer-Mediated Communication 19(1), 2013, pp. 38-55.

[36] Majchrzak, A., S. Faraj, G.C. Kane, and B. Azad, “The Contradictory Influence of Social Media Affordances on Online Communal Knowledge Sharing", Journal of Computer-Mediated Communication 19(1), 2013, pp. 38-55.

[37] Maksimenko, S., and L. Serdiuk, "Psychological potential of personal self-realization", Socai Welfare 1(6), 2016.

[38] Mathiesen, P., W. Bandara, and J. Watson, "The Affordances of Social Technology: A BPM Perspective", International Conference on Information Systems, 2013, pp. 3709-3719.

[39] Mesgari, M., and S. Faraj, "Technology Affordances: The Case of wikipedia", 18th Americas Conference on Information Systems, (2012), 3833-3841.

[40] Naim, M.F., and U. Lenka, "Linking knowledge sharing, competency development, and affective commitment: evidence from Indian Gen Y employees", Journal of Knowledge Management 21(4), 2017, pp. 885-906.

[41] Nicholas, D., Assessing Information Needs, Taylor \& Francis, Abingdon, UK, 2003.

[42] Norman, D.A., "The Design of Everyday Things", Human Factors and Ergonomics in Manufacturing 16, 2013.

[43] Pierce, J.L., and I. Jussila, Psychological ownership and the organizational context: Theory, research evidence, and application, Edward Elgar Publishing, 2011.

[44] Pierce, J.L., T. Kostova, and K.T. Dirks, "Toward a theory of psychological ownership in organizations", Academy of Management Review 26(2), 2001, pp. 298-310.

[45] Pierce, J.L., T. Kostova, and K.T. Dirks, "The State of Psychological Ownership: Integrating and Extending a Century of Research", Review of General Psychology 7(1), 2003, pp. 84-107.

[46] Potnuru, R.K.G., and C.K. Sahoo, "HRD interventions, employee competencies and organizational effectiveness: an empirical study", European Journal of Training and Development 40(5), 2016, pp. 345-365.

[47] Ryan, R.M., and E.L. Deci, "Self-regulation and the problem of human autonomy: does psychology need choice, self-determination, and will?", Journal of personality 74(6), 2006, pp. 1557-85.

[48] Sutcliffe, a. G., V. Gonzalez, J. Binder, and G. Nevarez, "Social Mediating Technologies: Social Affordances and Functionalities", International Journal of Human-Computer Interaction 27(11), 2011, pp. 1037-1065.

[49] Treem, J.W., and P.M. Leonardi, "Social Media Use in Organizations: Exploring the Affordances of Visibility, Editability, Persistence, and Association", In C.T. Salmon, ed., Communication Yearbook. New York, 2012, 143-189.

[50] Trieu, V.H., "Getting value from Business Intelligence systems: A review and research agenda", Decision Support Systems 93(1), 2017, pp. 111-124.

[51] Wan, Y., and Q. Gao, "An Ensemble Sentiment Classification System of Twitter Data for Airline Services Analysis", Proceedings - 15th IEEE International Conference on Data Mining Workshop, ICDMW 2015, IEEE (2016), 1318-1325.

[52] White, R.W., "Motivation reconsidered: The concept of competence", Psychological Review 66(5), 1959, pp. 297333.

[53] Wieneke, A., C. Lehrer, and R. Jung, "Exploring affordances of business intelligence \& analytics with regard to customer-oriented work practices", Pacific Asia Conference on Information Systems, PACIS 2016 Proceedings, (2016), 399.

[54] Yom-Tov, G.B., S. Ashtar, D. Altman, et al., "Customer Sentiment in Web-Based Service Interactions", International World Wide Web Conference Committee, (2018), 1689-1697.

[55] Zhang, J., Y. Zhang, Y. Song, and Z. Gong, "The different relations of extrinsic, introjected, identified regulation and intrinsic motivation on employees' performance: Empirical studies following self-determination theory", Management Decision 54(10), 2016, pp. 2393-2412.

[56] Zhang, Y., Y. Fang, K.-K. Wei, and H. Chen, "Exploring the role of psychological safety in promoting the intention to continue sharing knowledge in virtual communities", International Journal of Information Management 30(5), 2010, pp. 425-436.

[57] Zhou, F., R.J. Jiao, and J.S. Linsey, "Latent customer needs elicitation by use case analogical reasoning from sentiment analysis of online product reviews", Journal of Mechanical Design, Transactions of the ASME 137(7), 2015. 